\title{
COMPARACIÓN DE DOS MÉTODOS DE DETECCIÓN DE Spongospora subterranea f. sp. subterranea EN RAIICES DE PLANTAS HOSPEDERAS
}

Fecha de recepción: 21 de septiembre de 2013 • Fecha de aceptación: 13 de noviembre de 2013

\section{COMPARISON OF TWO DETECTION METHODS OF Spongospora subterranea f. sp. subterranea IN ROOTS OF HOST PLANTS}

Ivon Magaly Arcila Aristizabal ${ }^{6}$ Catalina María Zuluaga Amaya ${ }^{7}$ Maurio Alejandro Marín Montoya ${ }^{8}$ José Miguel

Cotes Torres ${ }^{9}$ Elena Paola González Jaimes ${ }^{10}$

\section{RESUMEN}

En esta investigación se compararon dos métodos de detección de Spongospora Aterranea f. sp. subterranea en raíces de plantas hospederas, mediante observación microscópica y PCR en tiempo real (qPCR).

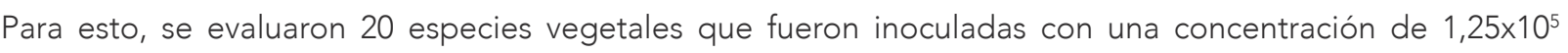
quistosoros. $\mathrm{g}^{-1}$ de suelo. Fue obtenida una muestra de raíz tres meses después de inoculación para determinar la presencia de estructuras morfológicas mediante dos metodologías: microscopía de luz previa tinción con azul de tripano y qPCR usando el sistema Taqman con los cebadores SponF y SponR y la sonda específica SponP. Estos cebadores amplifican un fragmento de 138 pb de la región ITS2 del ADN ribosomal. Para cuantificar la concentración de quistosoros en los tejidos evaluados, se realizó una curva estándar a partir de diluciones seriadas de $1,25 \times 10^{7}$ to $1,25 \times 10^{3}$ cystosori.mL-1, y se estimó el valor del ciclo umbral (Ct) para cada muestra desconocida con relación a la curva estándar. Finalmente, se analizaron los datos con el coeficiente de Kappa para determinar el grado de concordancia entre ambos métodos. Se encontró que los métodos utilizados presentaron un grado de acuerdo leve (0.19) en la detección e identificación de S. subterranea f. sp. subterranea en raíces de diversas plantas hospederas.

Palabras clave: Sarna polvosa, PCR en tiempo real, cuantificación del inóculo.

6. I. Agr. MSc. en Ciencias Agrarias. e-mail: imarcila@unal.edu.co Institución: Universidad Nacional de Colombia - Sede Medellín - Facultad de Ciencias Agrarias - Departamento de Ciencias Agronómicas - Cll. 59A No 63-20 - Núcleo El Volador, Medellín - Colombia.

7. I. Agr. MSc. Profesora Ocasional. e-mail: catazuluaga81@gmail.com Institución: Politécnico Colombiano Jaime Isaza Cadavid- Facultad de Ciencias Agrarias - Cr 48 \#7-151, Medellín - Colombia.

8. I. Agr. MSc. PhD. Profesor Asociado. e-mail: mamarinm@unal.edu.co Institución: Universidad Nacional Colombia - Sede Medellín - Facultad de Ciencias - Escuela de Biociencias - Cll. 59A No. 63-20 - Núcleo El Volador, Medellín - Colombia.

9. I. Agr. MSc. DSc. Profesor Asociado. e-mail: jmcotes@unal.edu.co Institución: Universidad Nacional Colombia - Sede Medellín - Facultad de Ciencias Agrarias - Departamento de Ciencias Agronómicas - ClI. 59A No. 63-20 - Núcleo El Volador, Medellín-Colombia.

10.I. Agr. MSc. DSc. Profesora Asociada. e-mail: epgonzalez@elpoli.edu.co Institución: Politécnico Colombiano Jaime Isaza Cadavid- Facultad de Ciencias Agrarias - Cr 48 \#7-151, Medellín - Colombia. 


\section{ABSTRACT}

This research was carried out to compare microscopic observation and quantitative PCR (qPCR) detection of Spongospora subterranea f. sp. subterranea in roots of 20 host plants. Plants were previously inoculated with a concentration of $1 \times 10^{5} \mathrm{~g}^{-1}$ of soil. Three months after inoculation a sample of roots was obtained and stained using the trypan blue dye in order to observe the presence of morphological structures of $S$. subterranea f. sp. subterranea under ligth microcopy. qPCR was tested using the Taqman system with primers SponF / SponR and the specific probe SponP, which amplify a 138 bp fragment of the ITS2 ribosomal DNA. A serial dilution from $1,25 \times 10^{7}$ to $1,25 \times 10^{3}$ cystosori. $\mathrm{mL}^{-1}$ was prepared and a standard curve built to estimate threshold cycle values (cT) and DNA concentration of each unknown sample. Finally, the Kappa coefficient was calculated to determine the degree of agreement of $S$. subterranea detection by both methods, obtaining a slight value of 0.19 .

Keywords: powdery scab, real-time PCR, inoculum, quantification.

\section{INTRODUCCIÓN}

El patógeno obligado Spongospora subterranea (Wallr.) Lagerh. f.sp. subterranea Tomlinson es el agente causal de la Sarna polvosa de la papa, una de las enfermedades más limitantes en la actualidad en Colombia y otros países andinos (Osorio et al., 2012). Actualmente está clasificado en el Reino Protozoa, División Myxomycota, Clase Plasmodiophoromycetes y Familia Plasmodiophoraceae (Merz y Falloon, 2009), en conjunto con otros fitopatógenos como Plasmodiophora brassicae, Polymyxa betae, Polymyxa graminis y Spongospora nasturtii que causan enfermedades de importancia económica en diversos cultivos y se caracterizan por tener un ciclo de vida en el cual se forman plasmodios multinucleados, zooesporas biflageladas y estructuras de resistencia (quistosoros) (Qu et al., 2006).

La plantas afectadas por sarna polvosa se caracterizan por presentar síntomas que incluyen pústulas polvorientas en la superficie de los tubérculos y agallas con forma de cuenta en las raíces de los hospederos, reduciendo la producción de los cultivos, la calidad de los tubérculos y por ende su comercialización (Shah et al., 2010). La sintomatología en los tubérculos puede cubrir hasta un 75\% de la epidermis afectando la calidad cosmética de la papa (Merz y Falloon, 2009), mientras que en las raíces afecta los procesos de absorción de agua y nutrientes (Falloon et al., 2005; Gilchrist et al., 2011).

La infección de S. subterranea f. sp. subterranea inicia con la liberación de las zoosporas por efecto de los exudados de las raíces y condiciones de humedad y temperatura del suelo (Harrison et al., 1997, Restrepo et al., 2010, Corrales et al., 2011). Las zoosporas pierden sus flagelos en contacto con el pelo radical y desarrollan una estructura por donde es depositado el contenido celular de la zoospora. La penetración de la pared de la célula hospedera se origina en un estilete o "Stachel" ubicado en un "Rohr" o tubo alargado en el interior de la zoospora, estas dos estructuras son características de los Plasmodiophoridos (Webster y Weber, 2007). Posteriormente, se forma un plasmodio uninucleado que 
sufre divisiones cruciformes dando origen a un plasmodio multinucleado o zoosporangio. De este zoosporangio se pueden liberar zoosporas secundarias o formarse estructuras de resistencia que pueden permanecer latentes por varias décadas en el suelo (Merz, 2008).

Además de la papa, se han reportado dos grupos de hospederos de S. subterranea f. sp. subterranea, un grupo denominado hospederos zoosporangiales y otro donde el patógeno puede cumplir todo su ciclo de vida, al desarrollar estructuras de resistencia o quistosoros. Así por ejemplo, Jones y Harrison (1972), reportaron observaciones zoosporangiales del patógeno mediante microscopía en Chenopodium album., Lapsana communis., Matricaria matricarioides, Poa annua, Rumex acetosella, Solanum sp. y Urtica dioica. En forma similar, Andersen et al. (2002) en Dinamarca reportaron 13 especies como hospederos zoosporagiales de S. subterranea f. sp. subterranea: Artemisia vulgaris, Chamomilla suaveolens, Chenopodium album, Galium aparine, Geranium pusillum, Matricaria inodora, Polygonum avicular, Polygonum convolvulus, Rumex acetosella, Solanum sp., Sonchus arvensis, Urtica urens y Viola tricolor.

A su vez, Qu y Christ (2006) evaluaron plantas de cultivos y arvenses comunes en Estados Unidos por microscopía de luz, encontrando que tomate (Solanum lycopersicum), mostaza amarilla (Brassica campestris) y avena (Avena sativa) presentaron quistosoros, además diez especies fueron definidas como hospederos zoosporangiales: Amaranthus retroflexus, Ambrosia artemisiifolia, Brassica napus, Chenopodium album, Cyperus esculentus, Datura stramonium, Fagopyrum esculentum, Phleum pratense, Raphanus sativus, Secale cereale, Trifolium pratense. Más recientemente, Nitzan et al. (2009), reportaron la formación de agallas por causa del patógeno en Solanum sarrachoides; y Shah et al. (2010), registraron a S. sarrachoides y a Solanum nigrum como plantas hospederas en Nueva Zelanda.
La detección de S. subterranea f. sp. subterranea, en raíces y tubérculos de plantas asintomáticas es un aspecto fundamental para el manejo de la sarna polvosa de la papa. Los primeros estudios de detección de S. subterranea f. sp. subterranea se realizaron utilizando bioensayos con plantas trampa como tomate y N. benthamiana (Merz, 1989). Posteriormente, Merz et al. (2005), describieron una prueba de bioensayos útil para la selección de cultivares de papa susceptibles a S. subterranea f. sp. subterranea en una etapa temprana de infección como una estrategia de apoyo a los programas de mejoramiento genético por resistencia a la sarna polvosa.

Las pruebas serológicas basadas en ELISA (Enzyme Linked Immunosorbent Assay) constituyen otra metodología útil para la detección de S. subterranea f. sp. subterranea. Sin embargo, la sensibilidad de éstas es usualmente limitada (de 100 a 1000 quistosoros $\mathrm{g}^{-1}$ suelo), y para el caso de algunos anticuerpos que sólo detectan el patógeno a partir de quistosoros (Walsh et al., 1996; Merz et al., 2005), la ocurrencia de estados plasmodiales y/o zoosporangiales puede resultar en falsos negativos.

Diversas pruebas moleculares se han diseñado para la detección específica de S. subterranea $f$. sp. subterranea en tubérculo, raíces y en suelo, con base en la amplificación por PCR de la región ITS del ADNr, siendo los cebadores más utilizados para tal fin:, Sps1/Sps2 (Bell et al., 1999), Spo8/Spo9 (Bulman y Marshall, 1998) y SsF y SsR (Qu et al., 2006). En general esta metodología ofrece altos niveles de sensibilidad (hasta $2,5 \times 10^{-5}$ quistosoros) y en teoría podrían detectar tan sólo una zoospora por reacción de PCR (Bell et al., 1999). Además la especificidad de los cebadores evita reacciones cruzadas con otros Plasmodiophoridos y cuando se acopla la técnica con la secuenciación de los amplicones obtenidos o su análisis de restricción (RFLPs), es posible la definición de variantes o ribotipos del patógeno (Osorio et al., 2012). 


\section{Esta investigación comparados metodologías de detección de S. subterranea f. sp. subterranea en 20 especies vegetales reportadas como hospederas del patógeno.}

En los últimos años, el desarrollo de la metodología de PCR en tiempo real han posibilitado además de la detección de los patógenos, cuantificar sus niveles de inóculo en tejidos infectados o muestras de suelos, aguas, alimentos, entre otros, previa construcción de curvas estándar (Van de Graaf et al., 2003; Ward et al., 2004). Así por ejemplo, utilizando qPCR (Van de Graaf et al., 2003) detectaron diferentes estados del ciclo de vida de S. subterranea f. sp. subterranea en raíces de plantas, así como quistosoros en suelo y agua; mientras que Ward et al. (2004) reportaron que mediante esta técnica es posible aumentar los niveles de sensibilidad en la detección del patógeno en tubérculos asintomáticos de papa, en al menos 100 veces con respecto a la PCR convencional y a las pruebas de ELISA. En dicho trabajo realizado en el Reino Unido, Ward et al. (2004) utilizaron un control interno (gen citocromo oxidasa de la papa) y 37 muestras de cáscara de tubérculos con y sin síntomas posibles de sarna polvosa procedentes de diferentes cultivares de dicho país, demostrando la universalidad de la técnica para la detección del patógeno y la posibilidad de evaluar la eficiencia/inhibición de las reacciones a partir del seguimiento del control interno. Por otra parte, Lees et al. (2008), encontraron que con la técnica de qPCR es posible detectar a S. subterranea f. sp. subterranea en suelos y en raíces de plantas trampa con una sensibilidad inferior a 2 quistosoros $\mathrm{g}^{-1}$ y mayor o igual a 0,5 quistosoros $\mathrm{mL}^{-1}$, respectivamente.
Más recientemente, Qu et al. (2011), desarrollaron una prueba de qPCR múltiple para determinar en una sola reacción sí la ocurrencia de síntomas de sarna en tubérculos de papa eran causados por S. subterranea $f$. sp. subterranea o por Streptomyces spp., el agente causal de la sarna común. Como técnicas de detección algunas investigaciones siguen la metodología de bioensayo (Merz et al., 2005), en conjunto con pruebas moleculares, para tener mayor confiabilidad en la detección del patógeno tanto de muestras de raíz como de suelo (Qu y Christ, 2006; Montero-Astúa et al., 2004), sin embargo, el usar más de una metodología incrementa los costos de la investigación.

Debido a la importancia creciente que representa la sarna polvosa de la papa en Colombia, es necesario avanzar en el estudio de su biología y epidemiología, siendo la definición del rango de hospedantes y la detección temprana del patógeno, aspectos fundamentales para implementar medidas de manejo de la enfermedad. Esta investigación buscó comparar dos metodologías de detección de (microscopía óptica de estructuras y qPCR) S. subterranea f. sp. subterranea en 20 especies vegetales frecuentemente encontradas en los ecosistemas altoandinos de Colombia y reportadas como hospederas del patógeno, con el fin de establecer el alcance de dos metodologías de detección asintomática (microscopía óptica de estructuras y qPCR) para el apoyo de estudios futuros de epidemiología de la enfermedad. 


\section{MATERIALES Y MÉTODOS}

\section{Localización y especies evaluadas}

La investigación se realizó en casa malla en la Estación Experimental Paysandú de la Universidad Nacional de Colombia, ubicada en el Corregimiento de Santa Elena, ciudad de Medellín, a una altura de $2500 \mathrm{msnm}$. Se evaluaron 20 especies entre cultivables y arvenses asociadas al cultivo de papa: Allium cepa L., Apium graveolens L., Brassica oleraceae L., Coriandrum sativum L., Daucus carota L., Pennisetum clandestinum Hochst. ex Chiov., Petroselinum crispum (Mill.) Nyman ex A.W. Hill, Phaseolus vulgaris L., Physalis peruvianum L., Pisum sativum L., Polygonum nepalense Meisn., Raphanus sativus L., Rumex crispus L., Solanum betacea Cav., Solanum lycopersicum Mill, Solanum nigrum, Solanum phureja, Solanum quitoense Lam., Sonchus oleraceus L., y Zea mays L.

Por cada especie fueron sembradas 14 plantas de las cuales 4 correspondían a testigos no inoculados. Las plantas estuvieron con riego manual cada dos días, y el experimento se repitió tres veces en semestres consecutivos para una mayor confiabilidad de la información.

\section{Inoculación de plantas}

Se utilizaron quistosoros provenientes de lotes de papa infestados con S. subterranea f. sp. subterranea, los cuales fueron extraídos y cuantificados siguiendo la metodología de Alzate et al. (2008), así se pesó 0,1 g de inóculo de suelo previamente macerado y tamizado por mallas de 90 y $25 \mu \mathrm{m}$. Luego, se adicionaron $10 \mathrm{~mL}$ de agua destilada en un tubo Falcon, se agitó y se tomó una alícuota de $10 \mu \mathrm{L}$ para cuantificar los quistosoros presentes en cada sección de la cámara de Neubauer. Se realizaron cinco conteos del inóculo, obteniendo un total de 50 lecturas.

Las semillas de cada material fueron germinadas en turba y cuando presentaron dos pares de hojas verdaderas, fueron trasplantadas a macetas con $2 \mathrm{~kg}$ de suelo, momento en el cual se aplicó el inóculo a razón de $1 \times 10^{5}$ quistosoros $\mathrm{g}^{-1}$ de suelo.

\section{Detección al microscopio de luz}

En el momento de la cosecha, el cual dependía del ciclo de vida de cada una de las especies consideradas en el estudio, las raíces fueron lavadas con agua corriente y examinadas de forma visual para detectar agallas macroscópicas.

La raíz fue teñida con azul de tripano al 0,05\% hasta cubrir las raíces dentro de un tubo Falcon de $15 \mathrm{~mL}$. Por cada muestra bajo análisis, se montaron cinco fragmentos de raíces, escogidos al azar, en un portaobjetos, siendo observadas en su totalidad mediante un microscopio de luz con aumento ocular de 10X, 40X y 100X con el fin de observar las estructuras asociadas a $S$. subterranea descritas por Hoyos et al. (2009).

\section{Detección y cuantificación por qPCR}

En la primera etapa, se realizó una curva estándar a partir de diluciones seriadas de quistosoros con agua ultrapura y tres réplicas por dilución. De esta forma, $100 \mathrm{mg}$ de quistosoros fueron diluidos en $10 \mathrm{~mL}$ de agua destilada y se procedió a su conteo directo utilizando una cámara de Neubauer, obteniéndose un promedio de 16'520.000 quistosoros $\mathrm{mL}^{-1}$ con base en cinco lecturas independientes. A partir de esta concentración inicial se preparó una suspensión de 12.500.000 quistosoros $\mathrm{mL}^{-1}$ y sus diluciones respectivas de 1:10 (1.250.000 quistosoros $\mathrm{mL}^{-1}$ ), 1:100 (125.000 quistosoros $\left.\mathrm{mL}^{-1}\right), 1: 1000$ (12.500 quistosoros $\mathrm{mL}^{-1}$ ) y 1:10000 (1.250 quistosoros $\mathrm{mL}^{-1}$ ).

Posteriormente se procedió a extraer el ADN de los quistosoros presentes en dichas diluciones, mediante el kit ULTRA Clean ${ }^{\mathrm{TM}}$ Soil ADN isolation (MO Bio Laboratories, EEUU) siguiendo las recomendaciones del fabricante. El valor de Ct fue calculado para cada muestra conocida con el software RotorGene O Series Software 1.7. 
La extracción en raíces se realizó con el kit DNeasy Plant mini (Qiagen, EEUU), siguiendo las instrucciones del fabricante, con elusión del ADN en 40 $\mu l$ de agua destilada estéril. Para la prueba de GPCR se utilizó el kit Maxima Probe/ROX qPCR Master Mix (2X) (Thermo, EEUU), utilizando los cebadores SponF (5'CTTTGAGTGTCGGTTTCTATTCTCCC3') y SponR (5'GCACGCCAATGGTTAGAGACG3) y la sonda TaqMan SponP (5' FAM-TCT TTC AAG CCA TGG ACC GAC CAG A- BHQ-1 3') que amplifican un fragmento de 138 pb de la región ITS2 del ADNr (Qu et al., 2011). El volumen de cada reacción fue de $25 \mu \mathrm{l}$ que contienen 12,5 $\mu \mathrm{L}$ de Maxima Probe /ROX qPCR Master Mix (2X) (Maxima ${ }^{\circledR}$ Hot Start Taq ADN polymerasa, dNTPs y buffer de reacción), 9,5 $\mu \mathrm{L}$ de agua libre de nucleasas, 0,75 $\mu \mathrm{L}$ de cada cebador $(10 \mu \mathrm{M})$, $0,5 \mu \mathrm{l}$ de sonda $(10 \mu \mathrm{M})$ y $1 \mu \mathrm{L}$ de ADN. Las amplificaciones de qPCR se llevaron a cabo en un equipo Rotor-Gene Q 5-plex Platform (Qiagen) con un paso de activación inicial de $95^{\circ} \mathrm{C}$ por 5 min, seguido por 45 ciclos a $95^{\circ} \mathrm{C}$ por 25 s y $60^{\circ} \mathrm{C}$ por 1 min. Las muestras positivas fueron aquellas que superaron el valor umbral (Ct) antes del ciclo 40 (Shena et al., 2004) y su cuatificación se realizó por regresión lineal con respecto a la curva estandar. La eficiencia de la reacción se calculó con la fórmula $E=10^{(-1 / \mathrm{m})}$, donde $E$ es la eficiencia de la amplificación y m la pendiente de la curva y la adquisición de fluorescencia se realizó durante la etapa de extensión. En todas las reacciones de GPCR, incluyendo las realizadas para la construcción de la curva estándar, siempre se incluyó un control negativo absoluto (todos los componentes de la reacción sin ADN molde).

Para las pruebas iniciales y con el fin de confirmar la especificidad de las reacciones, los productos obtenidos por qPCR, fueron separados por electroforesis en gel de agarosa al $2 \%$ y visualizados en un transiluminador de UV, con el sistema digital de análisis Bio Doc Analyze (Biometra, Alemania). Al menos un amplicón de cada especie vegetal determinada como positiva para S. subterranea f. sp. subterranea, fue purificada con el kit GeneJET ${ }^{\mathrm{TM}}$ Gel Extraction Kit (Fermentas, Lithuania) y secuenciada en ambas direcciones con los mismos cebadores utilizados en el GPCR, con el kit Big Dye Terminator Cycle Sequencing Ready Reaction (PE Applied Biosystems, EEUU), en la compañía Macrogen (Corea del Sur). Las secuencias obtenidas con cada cebador, fueron editadas mediante el software BioEdit 6.0.6, construyéndose secuencias consenso y confirmándose su validez por comparación con las bases de datos moleculares con el programa BlastN (http://www.ncbi. nlm.nih.gov/BLAST/Blast.cgi).

\section{Coeficiente de Concordancia}

Se utilizó el coeficiente de concordancia kappa (k) (Cohen J., 1960) con el fin de comparar los dos métodos en la detección de S. subterranea f. sp. subterranea, es decir, detección a través de observación directa al microscopio de luz y detección a través de $\mathrm{qPCR}$. El índice de Kappa ( $k$ ) se define como:

$$
\mathrm{K}=\frac{P_{0-} P_{e}}{1-P_{e}}
$$

Siendo $P$ la proporción de acuerdos observados y $P_{e}$ la proporción de acuerdos por azar. A partir de:

$$
P_{o}=\frac{\mathrm{a}+d}{N}
$$

Siendo $N$ el número total de individuos observados, a el número de ellos al que ambos métodos clasifican como positivo y d el número de ellos al que ambos métodos clasifican como negativo. Y:

$$
P_{e}=\frac{r t+s u}{N^{2}}
$$

Siendo $r t / N^{2}$ la estimación de la probabilidad de que ambos métodos clasifiquen como positivo a una muestra y su/ $\mathrm{N}^{2}$ la probabilidad de que ambos métodos clasifiquen como negativo una muestra por azar. 
Para interpretar el índice de kappa, Landis y Koch (1977) propusieron la siguiente escala de valoración: pobre $(k=0,00)$, leve $(0,01<k<0,20)$, aceptable $(0,21<k<0,40)$, moderada $(0,41<k<0,60)$, considerable $(0,61<k<0,80)$ y casi perfecta $(0,81<k<1,00)$.

\section{RESULTADOS}

\section{Cuantificación de quistosoros por qPCR}

Las diluciones de quistosoros realizadas para la construcción de la curva estándar, permitieron una amplificación consistente en el ensayo de qPCR con los primer SsF/SsR y la sonda SponP, con un coeficiente de determinación de $\mathrm{R}^{2}=0,96$ y una eficiencia de la reacción de 0,88. La concentración más baja a la cual fue posible realizar la detección del patógeno fue de $1,25 \times 10^{3}$ quistosoros $\mathrm{mL}^{-1}$, con un valor $\mathrm{Ct}$ promedio de 34,59, mientras que el valor Ct promedio para la concentración $1,25 \times 10^{7}$ quistosoros. $\mathrm{mL}^{-1}$ fue de 23,23.

\section{Detección morfológica y cuantificación molecular de S. subterranea f. sp. subterranea en diferentes hospederos}

El total de muestras potenciales para ser evaluadas fue de 840 plantas, todas fueron evaluadas por detección al microscopio, lo cual requirió un tiempo de seis meses, sin embargo sólo 280 plantas pudieron ser evaluadas por qPCR debido a los costos elevados de este método de detección aunque su implementación demoró solamente 2 meses.

En la evaluación por microscopía de luz y por pruebas moleculares, las plantas testigos, es decir aquellas que no fueron inoculadas, no presentaron estructuras al interior de las raíces ni fueron amplificadas por qPCR, lo cual muestra que los experimentos no presentaron infecciones no dirigidas. Por otra parte, se logró la detección de S. subterranea f. sp. subterranea por ambos métodos en muestras de plantas de A. cepa, C. betacea, D. carota, P. clandestinum, P. crispum, P. peruviana, P. sativum, $R$. sativus, S. lycopersicum, S. nigrum, S. quitoense, $S$. phureja y Z. mays. De igual forma, en las especies $A$. graveolens, C. sativum, P. vulgaris, R. crispus y S. oleraceae el patógeno fue detectado sólo por observaciones microscópicas y en la especie $P$. nepalense fue detectado sólo por qPCR. La especie B. oleracea fue negativa por los dos métodos (Tabla 1).

La detección de S. subterranea f. sp. subterranea en las muestras de las plantas evaluadas, varío en los valores de Ct entre 24,51 y 38,78 y las concentraciones estimadas de quistosoros de 100 a 7,168.706, siendo las especies S. lycopersicum, P. crispum, $S$. quitoense y $Z$. mays en las que se presentaron los mayores niveles de inóculo del patógeno y en $P$. sativum, $C$. betacea y $P$. nepalense donde se encontraron los menores niveles (Tabla 2).

\section{Índice de concordancia}

De un total de 280 muestras evaluadas por ambos métodos, se presentaron 17 y 196 acuerdos positivos y negativos, respectivamente; con un índice de kappa de 0,196, es decir, que el acuerdo observado está compuesto por un 19,6\% del acuerdo máximo y un 80,4\% del esperado por azar, clasificándose, según la escala de valoración de Landis y Koch (1977) como leve (Tabla 3).

El resultado indica que hay una débil concordancia entre la prueba de qPCR y la microscopía, presentándose en la prueba molecular 59 muestras positivas mientras que en la evaluación al microscopio se presentaron 42 muestras positivas, lo que corresponde a solamente 17 muestras en común por lo que el número de concordancias es menor que el de las discordancias. Asumiendo que una planta enferma es aquella que es detectada por cualquiera de los dos métodos, el porcentaje de plantas enfermas fue de $30 \%$, es decir 84 de las muestras evaluadas.

Por otro lado, asumiendo como método gold standard la observación visual de estructuras del patógeno 
Tabla 1. Detección por microscopio de luz y qPCR de S. subterranea f. sp. subterranea en raíces de plantas hospederas.

\begin{tabular}{|c|c|c|c|c|}
\hline Familia & Especie & Nombre Común & $\begin{array}{l}\text { Detección } \\
\text { Microscopía }\end{array}$ & $\begin{array}{l}\text { Detección } \\
\text { Molecular }\end{array}$ \\
\hline Alliaceae & Allium cepa & Cebolla de huevo & + & + \\
\hline Asteraceae & Sonchus oleraceae & Cerraja & + & - \\
\hline \multirow{4}{*}{ Apiaceae } & Apium graveolens L. & Apio & + & - \\
\hline & Coriandrum sativum L. & Cilantro & + & - \\
\hline & Daucus carota & Zanahoria & + & + \\
\hline & Petroselinum crispum & Perejil & + & + \\
\hline \multirow{2}{*}{ Brassicaceae } & Brassica oleracea L. & Repollo & - & - \\
\hline & Raphanus sativus & Rábano & + & + \\
\hline \multirow{2}{*}{ Fabaceae } & Phaseolus vulgaris & Frijol & + & - \\
\hline & Pisum sativum L. & Arveja & + & + \\
\hline \multirow{2}{*}{ Poaceae } & Pennisetum clandestinum & Kikuyo & + & + \\
\hline & Zea mays & Maíz & + & + \\
\hline \multirow{2}{*}{ Polygonaceae } & Polygonum nepalenses & Corazón herido & - & + \\
\hline & Rumex crispus & Lengua de vaca & + & - \\
\hline \multirow{6}{*}{ Solanaceae } & Solanum lycopersicom & Tomate & + & + \\
\hline & Physalis peruviana L. & Uchuva & + & + \\
\hline & Cyphomandra betacea & Tomate de árbol & + & + \\
\hline & Solanum nigrum & Hierba mora & + & + \\
\hline & Solanum quitoense & Lulo & + & + \\
\hline & Solanum phureja & Criolla Colombia & + & + \\
\hline
\end{tabular}

al microscopio, la sensibilidad de la detección por qPCR, es decir, la probabilidad que la planta presente estructuras del patógeno cuando un resultado positivo del qPCR es obtenido, fue de $62,68 \%$, mientras que la especificidad de la prueba, es decir, la probabilidad que la planta esté libre del patógeno cuando un resultado negativo del qPCR es obtenido, fue de $85,00 \%$.

\section{DISCUSIÓN}

La sarna polvosa representa un considerable riesgo económico para la producción y comercialización de papa en Colombia y otros países del mundo (Gilchrist et al., 2011; Falloon et al., 2005). La naturaleza de patógeno obligado de su agente causal, su 
Tabla 2. Cuantificación de S. subterranea f. sp. subterranea por qPCR en raíces de plantas hospederas utilizando el sistema Taqman® con los primers SponF y SponR y la sonda TaqMan probe SponP.

\begin{tabular}{|c|c|c|}
\hline Especie & $\begin{array}{l}\text { Rango } \\
\text { de Ct }\end{array}$ & $\begin{array}{c}\text { Rango de } \\
\text { Concentración } \\
\text { calculada } \\
\text { (quistosoros mL-1) }\end{array}$ \\
\hline Allium cepa & $31,93-38,05$ & $1,231-64,524$ \\
\hline Daucus carota & 32,85 & 35,700 \\
\hline $\begin{array}{c}\text { Solanum } \\
\text { lycopersicum }\end{array}$ & $29,92-32,18$ & $54,873-236,301$ \\
\hline $\begin{array}{l}\text { Pennisetum } \\
\text { clandestinum }\end{array}$ & $38,7-31,91$ & $810-65,450$ \\
\hline $\begin{array}{l}\text { Petroselinum } \\
\text { crispum }\end{array}$ & $28,4-34,23$ & $3,030-630,945$ \\
\hline Pisum sativum & $33,63-38,16$ & $266-21,547$ \\
\hline $\begin{array}{c}\text { Physalis } \\
\text { peruvianum }\end{array}$ & $33,18-38,78$ & $768-28,801$ \\
\hline $\begin{array}{l}\text { Polygonum } \\
\text { nepalense }\end{array}$ & $36,48-37,16$ & $2,190-3,409$ \\
\hline $\begin{array}{l}\text { Raphanus } \\
\text { sativus }\end{array}$ & $31,9-37,44$ & $112-65,652$ \\
\hline $\begin{array}{c}\text { Cyphomandra } \\
\text { betacea }\end{array}$ & $35,06-37,23$ & $2,098-8,533$ \\
\hline $\begin{array}{l}\text { Solanum } \\
\text { nigrum }\end{array}$ & $32,3-35,13$ & $8,139-50,672$ \\
\hline $\begin{array}{l}\text { Solanum } \\
\text { quitoense }\end{array}$ & $28,94-30,37$ & $176,990-445,728$ \\
\hline Zea mays & $24,51 \_30,31$ & $184,430-7,168,706$ \\
\hline $\begin{array}{l}\text { Solanum } \\
\text { phureja cv. } \\
\text { Colombia }\end{array}$ & $29,82-37,58$ & $100-253,250$ \\
\hline $\begin{array}{c}\text { Control } \\
\text { positivo } \\
\text { (Quistosoros) }\end{array}$ & $23,49-28,37$ & $130,049-15,159,434$ \\
\hline $\begin{array}{l}\text { Control } \\
\text { negativo }\end{array}$ & $>40$ & 0 \\
\hline
\end{tabular}

Tabla 3. Coeficiente de concordancia Kappa, para la comparación del método qPCR y microscopía óptica en la detección de S. subterranea f. sp. subterranea en raíces de plantas inoculadas.

\begin{tabular}{cccc}
\hline & \multicolumn{3}{c}{ Microscopía } \\
\hline Molecular & Negativo & Positivo & Total \\
\hline Negativo & 196 & 25 & 221 \\
\hline Positivo & 42 & 17 & 59 \\
\hline Total & 238 & 42 & 280 \\
\hline
\end{tabular}

capacidad de sobrevivir en estado latente por largos períodos de tiempo en el suelo y el amplio rango de hospederos alternos que presenta, hacen de su detección temprana un aspecto fundamental para el manejo de esta enfermedad (García et al., 2013). Diferentes métodos convencionales y moleculares se han desarrollado para la detección y la realización de estudios epidemiológicos de S. subterranea f. sp. subterranea, incluyendo bioensayos, observaciones microscópicas con tinción de raíces infectadas (Merz, 1989; Qu y Christ, 2006, Ramírez et al., 2013) y PCR y qPCR con cebadores específicos (van de Graaf, 2003; García et al., 2013).

En la presente investigación se utilizaron las metodologías de tinción de raíces y qPCR para la detección de S. subterranea f. sp. subterranea en raíces de plantas hospederas asintomáticas, a partir del for-

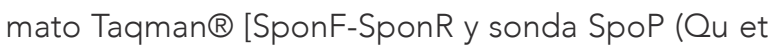
al., 2011)], realizando curvas estándar para comparar la concentración de quistosoros $\mathrm{mL}^{-1}$ del patógeno con las muestras bajo evaluación.

Las estructuras de S. subterranea f. sp. subterranea detectadas por microscopía están influenciada por el tipo de hospedero (Arcila et al., 2013) y la interpretación de las observaciones requiere de una considerable experiencia (Narayanasamy, 2008). En este estudio se observaron estructuras como zoosporangios y quistosoros, lo que permite hacer una interpretación del desarrollo de la enfermedad al 
poder categorizar los hospederos como zoosporangiales $\mathrm{u}$ hospederos con la capacidad de formar estructuras de resistencia (Qu y Christ, 2006, Andersen et al., 2002; Arcila, 2013). Una posible explicación a las diferencias halladas entre los dos métodos de detección en cuanto al número de plantas infectadas es que la detección de GPCR, pudo haber detectado fracciones de ADN de Spongospora subterranea f.sp. subterranea que no pudieron ser observadas como zoosporangios y/o quistosoros.

La capacidad en la detección de quistorosos por QPCR en esta investigación, tuvo un rango de diluciones de $1,25 \times 10^{7}$ a $1,25 \times 10^{3}$ con valores $\mathrm{Ct}$ de 23,23 y 34,59 respectivamente. Otros investigadores han detectado a $S$. subterranea f. sp. subterranea a partir de concentraciones más bajas, como las reportadas por Lees et al., (2008), quienes encontraron una mayor sensibilidad en la detección de S. subterranea f. sp. subterranea en suelo y en raíces de plantas trampa con $<2$ quistosoros por $\mathrm{g}$ de suelo y $\geq 0.5$ quistosoros $\mathrm{mL}^{-1}$, respectivamente. Ward et al. (2005) reportaron el desarrollo de un método por qPCR para la detección y cuantificación de Polymyxa graminis, en raíces de plantas y en suelo, pero en este caso con base en la detección directa de zoosporas y un rango de cuantificación $1 \times 10^{5}$ hasta 1 zoospora $\mathrm{mL}^{-1}$ correspondientes a valores $\mathrm{Ct}$ de 10 a 28 ciclos. Por su parte, Ward et al. (2004), compararon el nivel de sensibilidad de
QPCR y PCR convencional, con diluciones $10^{0} ; 10^{-1}$; $10^{-2} ; 10^{-3} ; 10^{-4}$ y $10^{-5}$ de $0,8 \mathrm{~g}$ de tejido de tubérculo con sarna polvosa, encotrando que cuando se compararon los puntos finales de dilución (10${ }^{4}$ y $10^{-5}$ ), los quistosoros pudieron ser detectados en la dilución final de sensibilidad de $10^{-5}$ para la GPCR, mientras que dicho valor fue de $10^{-3}$ para la PCR convencional. Van de Graaf et al. (2003), utilizando los cebadores SsTQF1 y SsTQR1 y la sonda SsTQP1, reportaron que con sólo $1 \mu \mathrm{L}$ de las series de diluciones de ADN estándar adicionada por reacción, equivalente a 100; $10 ; 1,0 ; 0,1 ; 0,025$ y 0,01 quistosoros de $S$. subterranea f. sp. subterranea, fue posible la amplificción de todas las muestras excepto aquella equivalente a 0,01 quistosoros. El valor $\mathrm{Ct}$ obtenido en dicho estudio para estimados de 0,025 quistosoros fue de 37 ciclos comparado con el valor $\mathrm{Ct}$ de 25 encontrado para el ADN equivalente a 100 quistosoros.

En la presente investigación la cantidad de quistosoros necesarios para la detección del patógeno fue muy alto en comparación con los reportes mencionados anteriormente, a pesar de que en los ensayos preliminares se evaluaron diluciones hasta de 1 quistosoro $\mathrm{mL}^{-1}$. Sin embargo los problemas de reproducibilidad encontrados entre las repeticiones generadas para la curva estándar como resultado de la inhibición de las reacciones de qPCR, solamente nos permitió iniciar nuestro rango de

Las estructuras de S. subterranea f. sp. subterranea detectadas por microscopía están influenciada por el tipo de hospedero (Arcila et al., 2013) y la interpretación de las observaciones requiere de una considerable experiencia (Narayanasamy, 2008). 
estimación a partir de 1250 quistosoros $\mathrm{mL}^{-1}$. La inhibición de las reacciones de PCR para la detección de S. subterranea f. sp. subterranea es frecuente y reportada en varias ocasiones (Osorio et al., 2012, García et al., 2013), debido a la ocurrencia en los tejidos de papa afectados por la sarna polvosa, de múltiples metabolitos secundarios como el ácido clorogénico y diferentes fenoles que afectan la eficiencia de las Taq-polimerasas. Sin embargo, gracias a que en el qPCR la detección se basa en las primeras fases de los ciclos de PCR y no depende de la acumulación exponencial de los productos finales, es posible la detección del patógeno aún bajo condiciones de inhibición parcial de las reacciones (García et al., 2013). Esta situación podría también explicar las diferencias entre las plantas que fueron positivas por la observación al microscopio y obtuvieron un resultado negativo en el método de qPCR.

La PCR en tiempo real permite además, gracias a su capacidad de cuantificación de inóculo primario y secundario, evaluar el nivel de infección de las raíces y medir los niveles de resistencia de los hospederos (Narayanasamy, 2008). Para este caso en particular, se encontró que los hospederos asíntomáticos P. crispum, S. lycopersicum, S. quitoense y Z. mays, son hospederos más permisivos de $S$. subterranea f. sp. subterranea con concentraciones de hasta 7.168.706, 445.728, 630,945 y 236,301 quistosoros $\mathrm{mL}^{-1}$, respectivamente, que las demás especies evaluadas en esta investigación.

Un aspecto a resaltar de los resultados, correspondió a los bajos niveles de concordancia encontrados entre los dos métodos evaluados para la detección del patógeno, con un índice de Kappa de 0,196 , lo que sugiere tres situaciones para la ejecución de las pruebas. La primera, es asumir que un valor positivo, es decir un resultado de planta infectada, es aquella planta que con cualquiera de las dos metodologías sea declarada como positiva, y la segunda es que al aplicar las dos metodologías se declare como planta enferma aquella planta que en ambas metodologías tuviera un resultado positivo. Estas dos primeras situaciones implican recursos económicos y de tiempo asociados a la ejecución de los sistemas de detección, la cual ha sido sugerida por Osorio et al. (2013). Sin embargo estas alternativas incrementan el número de falsos positivos para el primer caso ya que se suman los falsos positivos de cada metodología sobrestimando la presencia del patógeno en las plantas, mientras que para el segundo caso se incrementa el número de falsos negativos, subestimando la evaluación de la presencia del patógeno en las plantas.

Una tercera situación, es la necesidad de seleccionar alguno de los dos métodos, ya sea porque

Se encontraron bajos niveles de concordancia entre los dos métodos evaluados para la detección del patógeno, con un índice de Kappa de 0,196. 
sea un mejor método de detección, es decir más seguro, lo que comúnmente se asocia como el método gold standard, o ya sea por los recursos disponibles en el laboratorio o por parte de los usuarios finales. Como fortaleza del método de la detección por microscopia de luz se destaca el bajo costo en materiales para realizar esta metodología y la capacidad para identificar las estructuras del patógeno, pudiendo inferirse el grado de avance de la enfermedad, aunque como se indicó, es necesario un alto nivel de experticia para la identificación de los signos del patógeno y un tamaño de muestra adecuado. Por otro lado, la metodología de qPCR tiene como fortaleza la detección de cantidades mínimas del patógeno, que quizás no son visualizadas al microscopio y la posibilidad de cuantificación del inóculo (medido este por la cantidad de ADN); aunque se requiere mejorar el proceso de extracción de ADN para hacerlo más acorde con las características propias de los genotipos de papa y el tipo de suelos predominantes en las zonas altoadinas del país, ya que esto pudo contribuir a la baja sensibilidad y especificidad de la prueba mostrada en el presente estudio. Asimismo es necesario buscar alternativas de escala que permitan la realización de la prueba de qPCR a costos más accesibles para evaluar un mayor número de plantas.

\section{BIBLIOGRAFÍA}

1. Alzate D.E., Hoyos L.M. y González E.P. 2008. Factores que inciden en la liberación de zoosporas de Spongospora subterranea (Wallroth) Lagerheim f. sp. subterranea Tomlinson. Revista Facultad Nacional de Agronomía Medellín 61(2): 4503-4510.

2. Andersen B.A.B., Nicolaisen M., Nielsen N.M. 2002. Alternative hosts for potato mop-top virus, genus Pomovirus and its vector Spongospora subterranea f. sp. subterranea. Potato Research 45: 37-43.

3. Arcila I.M., González E.P., Zuluaga C.M., Cotes J.M. 2013. Alternate Hosts of Spongospora subterranea f. sp. subterranea identification in Colombia by Bioassay. Revista Facultad Nacional de Agronomía Medellín 66: 6987 - 6998.

4. Bell K.S., Roberts J., Verrall S., Cullen D.W., Williams N.A., Harrison J.G., Toth I.K., Cooke D.E.L., Duncan J.M. y Claxton J.R. 1999. Detection and quantification of Spongospora subterranea f. sp. subterranea in soils and on tubers using specific PCR primers. European Journal of Plant Pathology 105: 905-915.

5. Bulman S.R., Marshall J.W. 1998. Detection of Spongospora subterranea in potato tuber lesions using the polymerase chain reaction (PCR). Plant Pathology 47: 759-766.

6. Cerda J., Villarroel del P. L. 2008. Evaluación de la concordancia inter-observador en investigación pediátrica: Coeficiente de Kappa. Revista Chilena de Pediatría 79: 54-58.

7. Cohen J. 1960. A coefficient of agreement for nominal scales. Educational and Psychological Measurement 20: 37-46. 
8. Corrales C., Zuluaga C.M., Cotes J.M., González-Jaimes E.P. 2010. Determinación de las condiciones óptimas para la liberación de zoosporas de Spongospora subterranea en bioensayos. Tropical Plant Pathology 37: 239 - 245.

9. Falloon, R.E., Curtin D., Lister R.A., Butler R.C. 2005. Root function and growth of potato plants reduced by Spongospora subterranea infection. American Journal Potato Research 82: 68.

10. García B. N., Morales J.G., González P., Gutiérrez P. y Marín M. 2013. Detección y cuantificación de Spongospora subterranea f. sp. subterranea en plantas señuelo y cultivos de papa en Colombia mediante qPCR. Acta biológica Colombiana 18: 121-136.

11. Gilchrist E., Soler J., Merz U., Reynaldi S. 2011. Powdery scab effect on the potato Solanum tuberosum ssp. andigena growth and yield. Tropical Plant Pathology 36: 350-355.

12. Harrison J.G., Searle R.J., Williams N.A. 1997. Powdery scab disease of potato -a review. Plant Pathology 46: 1-25.

13. Hoyos L., Villegas M., González E.P. 2009. Observaciones histológicas de estructuras celulares asociadas a Spongospora subterranean f sp. subterranean en papa. Revista Facultad Nacional de Agronomía 62:5039-5045.

14. Jones R.A.C., Harrison, B.D. 1972. Ecological studies on potato mop-top in Scotland. Annals Applied Biology 71: 47-57.

15. Landis J.R., Koch G.G. 1977. The measurement of observer agreement for categorical data. Biometrics 33:159-174.
16. Lees A.K., van de Graaf P., Wale, S. 2008. The identification and detection of Spongospora subterranea and factors affecting infection and disease. American Journal of Potato Research 85: 247-252.

17. Merz U. 1989. Infectivity, inoculum density and germination of Spongospora subterranea resting spores: a solution culture test system. Bulletin OEPP 19: 585-592.

18. Merz U. 2008. Powdery Scab of Potato-Occurrence, Life Cycle and Epidemiology. American Journal of Potato Research 85: 241-246.

19. Merz U., Falloon R.E. 2009. Review - powdery scab of potato - increased knowledge of pathogen biology and disease epidemiology for effective disease management. Potato Research 52: 17-37.

20. Merz U., Walsh J.A., Bouchek-Mechiche K., Oberhansli T., Bitterlin W. 2005. Improved immunological detection of Spongospora subterranean. European Journal of Plant Pathology 111: 371-379.

21. Montero-Astúa M., Vasquez V. y Rivera C. 2004. Potato powdery scab, caused by Spongospora subterranea f. sp. subterranea, in Costa Rica. Potato Research 47: 25-34.

22. Narayanasamy, P. 2008. Molecular Biology in Plant Pathogenesis and Disease Management. Microbial Plant Pathogens Volume 1. Springer Science - Business Media B.V., New York (NY), USA, 250p.

23. Nitzan N., Boydston R., Batchelor D., Crosslin J., Brown C. 2009. Hairy nightshade is an 
alternative host of Spongospora subterranea, the potato powdery scab pathogen. American Journal Potato Research 86: 297-303.

24. Osorio I., Orozco M., Gutiérrez P., González P., Marín M. 2012. Variabilidad genética de Spongospora subterranea f. sp. subterranea en Colombia. Bioagro 24: 151-162.

25. Qu X.S., Christ B.J. 2006. The host range of Spongospora subterranea f. sp. subterranea in the United States. American Journal Potato Research 83: 343-347.

26. Qu X.S., Kavanagh J.A., Egan D., Christ B.J. 2006. Detection and quantification of Spongospora subterranea f. sp. subterranea by PCR in host tissue and naturally infested soils. American Journal of Potato Research 83: 21-30.

27. Qu X.S., Wanner L.A., Christ B.J. 2011. Multiplex real-time PCR (TaqMan) assay for the simultaneous detection and discrimination of potato powdery and common scab diseases and pathogens. Journal of Applied Microbiology 110: 769-777.

28. Restrepo J.A., Zuluaga C., Cotes J.M. y González E.P. 2011. Infección de Spongospora subterranea en esquejes de papa (Solanum tuberosum) var. Diacol Capiro proveniente de tres fuentes de inóculo. Revista Facultad de Ciencias Básicas 7: 58 - 71.

29. Schena L., Nigro F., Ippolito A., Gallitelli D. 2004. Real-time quantitative PCR: a new technology to detect and study phytopathogenic and antagonistic fungi. European Journal of Plant Pathology 110: 893-908.
30. Shah F.A., Falloon R.E., Bulman S.R. 2010. Nightshade weeds (Solanum spp.) confirmed as hosts of the potato pathogens Meloidogyne fallax and Spongospora subterranean f.sp. subterranea. Australasian Plant Pathology 39: 492-498.

31. van De Graff P.V., Lees A.K., Cullen D.W., Duncan J.M. 2003. Detection and quantification of Spongospora subterranea soil, water and tissue samples using real-time PCR. European Journal Plant Pathology 109: 589-597.

32. Walsh J.A., Merz U., Harrison J.G. 1996. Serological detection of spore balls of Spongospora subterranea and quantification in soil. Plant Pathology 45: 884-895.

33. Ward E., Kanyuka K., Motteram J., Kornyukhin D., Adams M. 2005. The use of conventional and quantitative real-time PCR assays for Polymyxa graminis to examine host plant resistance, inoculum levels and intraspecific variation. New Phytologist 165: 875-885.

34. Ward L.I., Beales P.A., Barnes A.V., Lane C.R. 2004. A Real-time PCR assay based method for routine diagnosis of Spongospora subterranea on Potato tubers. Journal Phytopathology 152: 633-638.

35. Webster J., Weber R. 2007. Introduction to the Fungi. Cambridge University Press. 3a edición, New York (NY), USA, 841p. 